\title{
Academic Challenges for Chinese Transfer Students in Engineering
}

\author{
Robert M. O'Connell \\ Nuerzati Resuli \\ University of Missouri--Columbia, USA
}

\begin{abstract}
This article describes a research study determining the most significant academic challenges experienced by Chinese transfer students in engineering at an American university. The survey-based study examined eight areas where transfer students may have academic difficulty and determined that the most significant of those concern transfer credit issues, student-instructor and student-student language difficulties, and classroom culture differences. The cultural differences, related to course syllabi, classroom discussion and group work, and frequency of assignments and exams, are partially explained in terms of a theoretical framework based on Hofstede's power distance and risk avoidance elements. Recommendations are made of ways to ease these challenges and make the intercultural experience richer for both the transfer students and their American hosts.
\end{abstract}

Keywords: academic challenges, Chinese transfer students, cultural elements

\section{INTRODUCTION}

Since 1978, when China began to form open relations with the international community, the number of Chinese students participating in study abroad programs has grown steadily (Griner \& Sobol, 2014; Liu, 2014). For example, in the 10-year period from 2008-2009 to 2018-2019, the number of Chinese college students in the United States grew from 98,000 to 369,000 (www.statista.com). In 2013-2014, 31\% of international students studying in the United States were Chinese, the largest such international group (Ching et al., 2017; Chao, 2017; Chao \& Hegarty, 2014). The phenomenon of Chinese students studying abroad will likely persist and continue to 
grow because knowledge and skills learned abroad are considered essential to China's future development (Griner \& Sobol, 2014; Liu, 2014).

The United States will likely continue to be a popular destination for Chinese students choosing to study abroad for several reasons. First, there is the prestige associated with a degree from the United States (Ozturgut \& Murphy, 2009), which would be helpful either in the job market or in gaining admission to a prestigious graduate school (Chao et al., 2017). Next, there are better internship and job opportunities in the United States than in most other countries (Griner \& Sobol, 2014; Montgomery, 2017). Also, whereas the Chinese educational system has traditionally focused on rote learning, the American system consists of an interactive studentcentered teaching style that includes group discussion and critical thinking (Liao \& Wei, 2014), which many Chinese students and their families believe to be an important skill (Chao, et al., 2017). Finally, many Chinese believe that a U.S. college education will make them both globally employable and professional leaders when they return to China (Ching et al., 2017).

International students pay higher fees than do domestic students, and they boost local economies, thus providing a significant economic benefit. They also add a rich diverse cultural component to the campus and local communities, and they provide a boost to the international/global reputation of the university (Ching, et al., 2017; Ozturgut \& Murphy, 2009; Wu et al., 2015). Given the benefits derived from hosting international students, host institutions need to be aware of some of the unique challenges facing those students so that appropriate helpful measures can be taken to alleviate those challenges. While all new students, domestic and international alike, are faced with challenges adjusting to both the social and academic environments in their new settings (Gebhard, 2012; Ozturgut \& Murphy, 2009; Tas, 2013; Wu et al., 2015), international students usually have greater difficulty adjusting and take much longer to do so. Cultural differences, including lack of fluency in English, contribute to those difficulties.

Social problems encountered by international students in the United States include difficulty establishing strong cross-cultural friendships, and homesickness and loneliness (Henze \& Zhu, 2012; Ozturgut \& Murphy, 2009). While these and other social challenges are important, the focus of this article is on the academic adjustment problems encountered by Chinese students in the United States, although social and academic problems are interrelated.

Since Chinese students comprise, by far, the largest international group on our campus (the University of Missouri-Columbia), and since cultural differences vary from country to country, the present study focused on Chinese students only, who have transferred in either after studying engineering for 2 years at a Chinese university and then finish their undergraduate engineering degree in the United States (Two-Plus-Two students); or after studying engineering for 3 years at a Chinese university and then earning their Master's degree in engineering in the United States (Three-Plus-Two students). Thus, transfer students, for this article, are a subset of Chinese international students, who have studied engineering at Chinese universities for 2 or 3 years before enrolling in the United States in one of the two abovementioned programs. Our main concern in this study was with students who have been exposed to an American university culture after being exposed to the Chinese 
university culture for 2 or 3 years. After 2 or 3 years in the Chinese higher education system, students will likely have become accustomed to certain practices in the university-level learning environment. Upon subsequently entering the American higher education system, they are likely to encounter a culture shock of sorts, e.g., practices and customs that differ from those they had become accustomed to in China, some of which could cause academic learning difficulties or challenges. Students who come to the United States right out of high school will not have formed any strong preconceptions about university academic life, so their experiences could be quite different from those of transfer students. As we have very few of those nontransfer students at this university and significant numbers of transfer students, whose experiences here we wish to improve, this project focused only on transfer students. A comparison of the academic cultural experiences of the two groups could be the subject of a further study.

The surveys described below were framed in terms of the differences between university learning environments in the United States and China, and the academic difficulties those differences may cause. The Two-Plus-Two and Three-Plus-Two students in the programs in question are exclusively engineering students. Transfer students in other academic areas may experience different learning environment differences and consequent academic challenges, so the scope of the research was limited accordingly. The research question for the project was: "What are the academic challenges encountered by Chinese engineering transfer students?" A survey-based study was conducted to determine answers to that question.

\section{LITERATURE REVIEW}

Here we first establish the cultural theoretical framework behind the project, and then summarize some important studies that illustrate the role of cultural differences, including Hofstede's (1997) "power distance" and "uncertainty avoidance" elements, in the academic adjustment challenges experienced by international Chinese college students.

\section{Theoretical Framework: The Role of Culture in Academic Challenges}

Various theoretical frameworks have been used in studies of Chinese students' adjustment to college life in foreign countries. For example, Montgomery (2017) used a "4S System" (situation, self, support, and strategies) based on Schlossberg et al. (1995) as "a foundation for understanding the common elements of individuals' transition experiences." Liao and Wei (2014) and Wu et al. (2015) used a popular theoretical model of the acculturation process due to Berry et al. (1987) in their studies of international students' adjustment to college life in the United States

For this project, it was hypothesized that academic challenges faced by Chinese international students are caused in large part by certain historical national cultural differences, which are reflected in the teaching and learning systems of China and the United States. Such national cultural differences are described well in Hofstede's (1997) five cultural elements, which reflect national identity and include large versus small power distance in relationships between the individual and authority, 
collectivism versus individualism, femininity versus masculinity, strong versus weak uncertainty or risk avoidance, and long-term versus short-term life orientation. Whereas Chinese culture is characterized by large power distance, low individualism, femininity, strong uncertainty avoidance, and a long-term life orientation, American culture is characterized by small power distance, high individualism, masculinity, low risk avoidance, and a short-term life orientation. The Chinese and American cultures are thus located at opposite poles of the spectrum defined by these elements (Hofstede, 1997), which can affect the relationships between Chinese transfer students and their non-Chinese instructors, and between Chinese transfer students and their American fellow students. Thus, in order to be academically successful in the United States, Chinese students must adapt to the differences in the teaching and learning systems of the two very different cultures.

For this project, furthermore, two of Hofstede's cultural elements, power distance and uncertainty avoidance, were hypothesized as being particularly influential in the classroom, and thus used as the theoretical framework. As stated above, American culture is characterized by small power distance and low risk avoidance, and Chinese culture is characterized by large power distance and high risk avoidance. Thus, in the American classroom, American students are often neither overly inhibited about interacting with instructors nor overly fearful of making mistakes. As observed by one Chinese student, "American students were very active during a class. Besides raising questions when invited by professors, they often made uninvited interruptions" (Zhang \& Xu, 2007). Chinese students, on the other hand, "feel uncomfortable participating in classroom discussions, asking questions in class, and having critical arguments," (Ching, et al., 2017). This is because, at least in part, "Chinese students view their professors as authority figures," and thus "they may not feel comfortable challenging the opinions of their professors" (Ching et al., 2017). In our experience, Chinese transfer students are both highly respectful of and deferential to the instructors and only willing to ask questions and participate when they are very sure of themselves.

\section{Academic Adjustment Issues for Chinese International Students: Relation to Culture Differences}

Some or all of Hofstede's cultural elements have been used as the theoretical framework for several studies. Tas (2013), for example, used all five of them to discuss the challenges experienced by international students generally in the United States. Using numerical indices to quantify each element, he presented data showing that the differences for power distance and uncertainty avoidance (the two elements of interest here) between the United States and the Asian countries of Taiwan, South Korea, and Japan are the same as for the United States and China. Thus, those cultural differences appear to be an Asian, not just Chinese, versus western phenomenon. Also, Ching et al. (2017) used "cultural distance" as defined by Redmond (2000) as the theoretical framework in their study of challenges faced by Chinese students in the United States. Interestingly, this "cultural distance" is defined by four elements that are identical to four of those defined by Hofstede (power distance, uncertainty avoidance, individualism/collectivism, and femininity/masculinity). 
In their study of academic challenges experienced by Chinese graduate students in the United States, Zhang and Xu (2007) identified several classroom-related areas where the two cultures differ, thus causing adjustment challenges for the Chinese students, and they explained how those differences illustrate some of Hofstede's causative cultural elements. One such area is what we call the "syllabus issue."

In the United States, instructors often provide detailed syllabi that include assignments and their due dates, dates for tests and quizzes, grading standards, and other important information. Such is generally not the practice in China, where syllabi are often not provided and "the professor decided everything as the semester was going, and students hardly had any clue about the overall schedule of a course" (Zhang \& Xu, 2007). Furthermore, "As a result of the lack of recognition of the importance of a course syllabus in the beginning of a semester (in the United States), students reported frustrating experiences later in the semester" (Zhang \& Xu, 2007). These frustrations concerned unawareness of the importance of assignments and their timely completion in final grades, and the frequency of exams throughout the semester. In China, the final exam is the primary, if not the only, mechanism used to determine final grades (Aubrey, 1991; Ozturgut \& Murphy, 2009). Thus, it appears that a significant cause of the academic challenges experienced by Chinese transfer students may be that they initially ignore course syllabi and fail to recognize the importance of assignments and their timely completion, or of the importance of quizzes and tests throughout the semester.

The syllabus issue appears to illustrate the difference in power distance or relationship to authority between the Chinese and American cultures. As stated previously, Chinese culture is characterized by large power distance, which helps explain why college instructors are treated with great respect and deference, and the teaching process is highly teacher-centered. It is characterized by greater freedom for the instructor and less accountability, as would be reflected by the requirement to provide and follow a syllabus. American culture, on the other hand, is characterized by small power distance, so that instructors and students are on a more familiar level than in China, with the result that teaching is more student-centered, and instructors are more accountable than in China. Thus, the syllabus may be thought of as a contract of sorts, from which the student knows what they must do to be successful in the course, and final grades are less arbitrary than in a large power distance setting. The syllabus issue will be seen to play a significant role in the transfer credit problem, as explained in the results section below.

Another classroom-related area identified by Zhang and Xu (2007) where the two cultures differ, thus causing adjustment challenges for Chinese transfer students, is in student participation in the classroom process, including participation in class discussions, and asking and answering questions, which are common aspects of student-centered active learning in the United States, but which is much less common in China. Many of the students in the Zhang and Xu study stated that in China "the lecture was the only instructional method, and students seldom participated in the instructional process." In addition to linguistic difficulties, which caused some Chinese international students to avoid speaking in class, others preferred to remain silent because they feared making mistakes and becoming embarrassed. This reflects the difference in uncertainty avoidance between the two cultures. 
The role of cultural differences in Chinese students' academic challenges in the United States is illustrated in many similar studies. For example, Ozturgut and Murphy (2009) suggested that "unfamiliarity with the American educational system is a significant cause of Chinese students' academic problems," which leads to "frustration, confusion, and anxiety" (Ching, et al., 2017), and they listed "studentteacher relationships, academic credits, grading scales, class attendance, and types and frequency of quizzes, exams, presentations, and assignments" as examples of academic problem areas.

Concerning student-teacher relationships, according to Ching et al., (2017; Gebhard, (2012); Liao \& Wei, (2014); and Wu et al., (2015), "Asian students have been trained to sit quietly in lecture-type classes and take detailed notes to be memorized in preparation for exams that are usually given only once or twice a year." Furthermore, "Chinese students view their professors as authority figures in their fields, and they may not feel comfortable challenging their opinions." These descriptions are characteristic of the so-called Confucian heritage learner (Yen, 1987; Henze \& Zhu, 2012). In contrast with this, the atmosphere in the American classroom is less formal than in China; students are active and even joke with the teacher (Yuan, 2011).

Participation in classroom discussion, wherein students ask and answer questions and conduct critical arguments, a common practice in the American classroom, is very difficult for Chinese students because they are generally unfamiliar with the whole process (Ching et al., 2017; Yuan, 2011). According to Yuan (2011), "Chinese students have the tendency to be quiet and not to speak up." Also, "it is considered impolite to talk excessively about personal opinions" (Ching et al., 2017). Henze and Zhu (2012) noted that the use of advanced language skills, slang, and digression into topics not directly related to the academic issue in question, add to Chinese students' difficulty in participating in classroom discussions. Ironically, as noted above, one of the reasons Chinese students choose to study here is to develop the skill of interactive critical thinking, but when exposed to it, they have difficulty. Henze and Zhu (2012) also noted that "learning to observe the new academic rules" is another cultural challenge to Chinese students. For example, in contrast with the Chinese system, the U.S. system "stresses consistent performance (continuous assessment) throughout the semester. Attendance and daily assignments are important parts of final grades. In China, on the other hand, class attendance is less important because one's performance on the final exam determines the final grade" (Yuan, 2011).

Finally, Tang et al. (2018) concisely described Chinese international students' academic challenges in terms of "language proficiency, different teaching style, and different evaluation process."

\section{METHOD}

To determine the academic challenge areas and their severity encountered by our Chinese transfer students, a three-part Institutional Review Board-approved survey questionnaire was developed. The first part of the survey consisted of the following questions to determine some basic background information. 
1. Are you a male or a female?

2. Which province and city/town in China are you from?

3. At which university in China were you a student before transferring here?

4. In which province and city/town is that university?

5. Are you in the Two-Plus-Two program or the Three-Plus-Two program?

6. What is your academic discipline, e.g., civil engineering?

The second and third parts of the survey were designed, respectively, to compare the classroom learning environments of China and the United States, and to determine the difficulty experienced by the Chinese transfer students in various academic areas. The reason for examining learning environment differences and resulting academic challenges was that, as will be seen in the Results section, most of the learning environment differences can be associated with either or both of Hofstede's cultural elements, and most of the academic challenges can be associated with the learning environment differences, thus establishing a connection between the transfer students' academic difficulties and our theoretical framework.

In the second part of the survey, participants were asked to consider the nine items in Table 1 and to rate each one as either not very different, slightly different, or very different. The nine items were developed based on ideas suggested in the literature review. Thus, Items $\mathrm{A}, \mathrm{G}, \mathrm{H}$, and I were derived primarily from the discussion of the syllabus issue and the literature cited therein (Zhang \& Xu, 2007; Ozturgut \& Murphy, 2009); and Items B-F were derived from the discussion of student participation in the classroom process and the literature cited therein (Ching, et al., 2017; Henze \& Zhu, 2012; Yen, 1987; Yuan, 2011).

\section{Table 1: Survey Items Used To Study Learning Environment Differences}

Instruction: Please indicate the degree to which each item differs between China and the United States (not very different, slightly different, or very different)
A. The use of detailed syllabi in courses
B. The amount of time the instructor spends literally lecturing during class
C. The amount of time the instructor spends answering questions during class
D. The amount of class time spent on class discussion
E. The amount of class time spent working on problems with classmates
F. The friendliness and informal atmosphere of the classroom
G. Class attendance requirements
H. The number of graded assignments in courses
I. The number of graded exams throughout the semester

All nine items can arguably be associated with either or both of Hofstede's power distance and uncertainty avoidance elements, as follows: Items A, B, and F-I with 
the power distance element, Items $\mathrm{D}$ and $\mathrm{E}$ with the uncertainty avoidance element, and Item $\mathrm{C}$ with both elements.

The third part of the survey was designed to determine the difficulty experienced by the Chinese transfer students in various academic areas. The survey participants were asked to consider the eight items listed in Table 2, and to rate each one as either not very difficult, slightly difficult, or very difficult. As in the case of Items B-F in Table 1, Items $\mathrm{C}-\mathrm{F}$ in Table 2 were derived from the discussion of student participation in the classroom process and the literature cited therein (Ching et al., 2017; Henze \& Zhu, 2012; Yen, 1987; Yuan, 2011). Item B was derived from the language issue as discussed in Zhang and $\mathrm{Xu}$ (2007) and Henze and $\mathrm{Zhu}$ (2012). Item A, related to the transfer credit problem, was alluded to in Ozturgut and Murphy (2009), but it has been a significant issue in our experience with Chinese transfer students. Finally, Items $\mathrm{G}$ and $\mathrm{H}$ were derived from reflection on the language problem and its possible consequences. If language is a challenge, to what extent does it impact transfer students' willingness to approach their instructors for help outside of class (Item G); and, similarly, to what extent does it impact students' ability to earn the grades they think they deserve?

Difficulty asking questions in class (Item C) can arguably be associated with both large power distance and uncertainty avoidance elements; difficulty participating in class discussions or in group work (in or outside the classroom; Items D-F) are more related to a large uncertainty avoidance element; and difficulty obtaining appropriate transfer credit (Item A) or seeking instructor help outside the classroom (Item G) can be associated with a large power distance. In this part of the survey, participants were also asked to optionally comment on their responses to any of the items in Table 2.

\section{Table 2: Survey Items Used To Study Academic Adjustment Difficulties}

Instruction: Please rate the encountered difficulty level of each academic item listed. (not very difficult, slightly difficult, or very difficult)

A. Obtaining appropriate transfer credit for courses taken in china

B. Understanding the instructor's english during class

C. Asking questions during class

D. Participating in class discussions

E. Working with classmates during group work sessions in class

F. Forming friendships with non-chinese classmates for study purposes

G. Meeting with instructors outside of class for help

H. Getting good grades in courses

Finally, as a fourth component of the survey, participants were asked to optionally elaborate on the three or four most challenging academic issues they have had as a transfer student.

Before administering the survey, it was given to a recent graduate of the TwoPlus-Two program and to a Chinese postdoctoral student, both of whom read the questions carefully and provided feedback to ensure that the questions were clear and unambiguous. 
To conduct the research, an email message explaining the project and soliciting participation was sent to all 148 Two-Plus-Two and Three-Plus-Two students in the College of Engineering along with statements guaranteeing privacy and clarifying that participation was voluntary. Forty-four students chose to participate, for a response rate of $29.7 \%$. There was no further contact with the 104 students who chose not to participate. The invitation email message included a link to an online survey instrument (Google Form), which collected and summarized the data presented and discussed in the Results section below.

\section{RESULTS}

\section{Demographic Information}

The demographic information questions revealed that the 44 participants consisted of 25 men and 19 women from 19 different provinces or municipalities in eight different regions throughout China and that they attended 16 different universities in 12 different Chinese cities. Thus, the participant pool consisted of transfer students from all throughout China, so that the academic difficulties they encountered here were assumed to be descriptive of Chinese students generally and not as pertaining to students from only one or two areas in China.

The demographic questions also revealed that 25 and 19 students, respectively, were participating in the Two-Plus-Two and Three-Plus-Two programs, and that they were in nine different engineering disciplines. Thus, the participant pool represented a reasonable cross-section of the Chinese transfer student body in engineering.

\section{Learning Environment Differences}

The results of the second part of the survey are summarized in Table 3, which shows, for each of the 11 items, the percentage of participants who responded not very different, slightly different, and very different. For discussion, the last column in the table shows the sum of the third and fourth columns - that is, the percentage of participants who responded either very different or slightly different.

Considering very different responses only (Column 4 in Table 3), it can be seen that between $23 \%$ and $52 \%$ of the respondents found every item in the table to be very different between the two countries. When slightly different responses are added to very different responses (Column 5), the percentages range from $68 \%$ to $91 \%$. Thus, there are significant differences between the learning environments in China and the United States in every one of the 11 items considered. The most significant differences in the learning environments of the two countries appear to be in Items A: "Use of a detailed syllabus"; D: "Class time spent on class discussion"; J: "The number of graded exams"; and K: "The difficulty of graded exams." As mentioned above, the difference data for every item in Table 3 can be associated with differences in either or both of Hofstede's power distance or uncertainty avoidance cultural elements. 
Table 3: Summary of Learning Environment Difference Data (\%)

\begin{tabular}{llcccc}
\hline \multicolumn{1}{c}{ Item } & $\begin{array}{c}\text { Not very } \\
\text { different }\end{array}$ & $\begin{array}{c}\text { Slightly } \\
\text { different }\end{array}$ & $\begin{array}{c}\text { Very } \\
\text { different }\end{array}$ & $\begin{array}{c}\text { Slightly } \\
\text { or very } \\
\text { different }\end{array}$ \\
\hline A. & Detailed syllabus & 13.6 & 36.4 & 50.0 & 86.4 \\
B. & Time spent lecturing & 27.3 & 40.9 & 31.8 & 72.7 \\
C. & Time answering questions & 25.0 & 36.4 & 38.6 & 75.0 \\
D. & Time for class discussion & 7.0 & 44.2 & 48.8 & 93.0 \\
E. & Time for group work & 20.9 & 44.2 & 34.9 & 79.1 \\
F. & Informal classroom & 27.3 & 36.4 & 36.4 & 72.7 \\
G. & Attendance requirements & 31.8 & 45.5 & 22.7 & 68.2 \\
H. $\quad$ Number of assignments & 13.6 & 43.2 & 43.2 & 86.4 \\
I. $\quad$ Number of exams & 9.1 & 38.6 & 52.3 & 90.9 \\
\hline
\end{tabular}

\section{Academic Adjustment Difficulties}

The results of the third part of the survey are summarized in Table 4, which shows, for each of the eight items, the percentage of participants who responded not very difficult, slightly difficult, and very difficult. For discussion, the last column in the table shows the sum of the third and fourth columns, that is, the percentage of participants who responded either slightly difficult or very difficult.

Table 4: Summary of Academic Difficulty Data (\%)

\begin{tabular}{llcccc}
\hline \multicolumn{1}{c}{ Item } & $\begin{array}{c}\text { Not very } \\
\text { different }\end{array}$ & $\begin{array}{c}\text { Slightly } \\
\text { different }\end{array}$ & $\begin{array}{c}\text { Very } \\
\text { different }\end{array}$ & $\begin{array}{c}\text { Slightly } \\
\text { or very } \\
\text { different }\end{array}$ \\
\hline A. & Transfer credit & 29.5 & 54.6 & 15.9 & 70.5 \\
B. & Instructor's English & 27.3 & 52.3 & 20.4 & 72.7 \\
C. & Asking questions in class & 47.7 & 25.0 & 27.3 & 52.3 \\
D. & Class discussions & 54.5 & 36.4 & 9.1 & 45.5 \\
E. $\quad$ Group work in class & 50.0 & 43.2 & 6.8 & 50.0 \\
F. Forming study groups & 51.2 & 32.6 & 16.2 & 48.8 \\
G. $\quad$ Outside instructor help & 81.8 & 15.9 & 2.3 & 18.2 \\
H. Getting good grades & 55.8 & 44.2 & 0.0 & 44.2 \\
\hline
\end{tabular}

Note that Items $\mathrm{C}, \mathrm{D}$, and $\mathrm{E}$ in Table 4 are similar to Items $\mathrm{C}, \mathrm{D}$, and $\mathrm{E}$, respectively, in Table 3 . Thus, as would be expected, in some cases, academic difficulties in the classroom arise because of differences in the classroom cultures of the two countries. Interestingly, the difficulty data for the three items, $52 \%, 46 \%$, and $50 \%$, respectively, are significantly lower than the difference data in Table 3 for the same three items, $75 \%, 93 \%$, and $79 \%$, respectively. This suggests that, while many transfer students have difficulty adjusting to some features of the new classroom environment, significant numbers of them are able to adjust to it. This may reflect a characteristic of engineering students, who tend to be relatively persistent, but further research would be needed to ascertain it. 
The results in Table 4 also show that the most serious academic issues encountered by the participants were difficulty obtaining appropriate transfer credit (Item A) and difficulty understanding their instructors' English (Item B). It appears that a major contributing factor to the transfer credit problem is that detailed descriptions, i.e., syllabi, of courses offered at the Chinese schools are very difficult to obtain, i.e., the above described syllabus issue. Recall Item A in Table 3 in which over $86 \%$ of the students stated that the use of a detailed syllabus, common in the United States, is not a common practice in Chinese courses. Students frequently stated that in many of their courses in China, they are not provided with a syllabus. This makes it very difficult to properly and efficiently assign transfer credit to incoming Chinese transfer students. One consequence of this is that transfer students often find themselves in courses in which they have previously studied most, but not all, of the content in a course in China, or they are placed in courses here in which most of the content is too advanced for them. Both situations can lead to frustration, boredom, and poor performance. In some cases, graduation is delayed because the student has to take more courses here than he or she had originally planned for. As explained in the Literature Review, the syllabus issue can be associated with Hofstede's power distance cultural element.

The following comment from one participant illustrates the transfer credit problem.

How I wish the transfer of credits could be faster or we could take some courses without prerequisites, maybe some permission code or something. It take one extra semester to graduate because the first semester I have almost no professional classes to take.

Another serious academic difficulty, as indicated by Item B in Table 4 is that almost $73 \%$ of the transfer students have trouble understanding their instructors' English. Although the Chinese students study English in China and become sufficiently proficient to pass the Test of English as a Foreign Language (TOEFL) and other language proficiency tests, most of them are simply not fluent enough to be as comfortable in the classroom as those students for whom English is their first language.

Language also plays a role in the difficulties indicated in Items $\mathrm{C}-\mathrm{F}$ in Table 4, which shows that between $46 \%$ and $52 \%$ of the students find it difficult to ask questions in class, participate in class discussions or group work, or form study groups with non-Chinese classmates. The following verbatim comments from some of the respondents illustrate how language difficulties influence Items $\mathrm{C}-\mathrm{F}$. Besides the contents in these examples illustrating that English poses challenges, the relatively poor grammar used therein further illustrates the point.

On Item C: Asking questions in class:

- "It's hard to catch up with native students and teachers when I first came here. And another thing is that I will be scared of I cannot ask question fluently." 
- "Asking questions in class makes me feel stressed because most of the time, instructors can't perfectly understand what I am asking about......So, I prefer to ask them after class."

- "Sometimes you are not willing to ask because of the concern of accent."

On Item D: Participating in class discussions:

- "My English skill was not sufficient enough for me to explain my ideas well at the beginning of my academic program."

- “... don't know how to express the opinion properly."

- "Sometimes, it makes me embarrassing to discuss with classmates, though they are friendly and willing to listen to me. But I just cannot express my point of view fluently and accurately."

On Item E: Participating in group work in class:

- "The most difficult part is discussing the course content in English. We learnt the necessary concepts and keywords of engineering area in Chinese. When I first came here, we didn't have enough vocabularies for listening and speaking. It took me more time to fully understand the concepts presented in another language. After I understood the topic to discuss, I started to look for words to explain my ideas."

- $\quad$...not easy to talk to other American students.

On Item F: Forming study groups with non-Chinese classmates:

- "At the beginning of my study in MU, oral speaking in English was my largest barrier."

- “... English not very good.”

Besides the role of language in the difficulties associated with Items $\mathrm{C}, \mathrm{D}$, and $\mathrm{E}$ in Table 4, as stated above, these three items can also be associated with Hofstede's cultural elements. The following comments from some of the respondents illustrate how Hofstede's power distance (indicated by PD) and uncertainty avoidance (indicated by UA) elements influence Items $\mathrm{C}, \mathrm{D}$, and $\mathrm{E}$.

On Item C: Asking questions in class:

- “... not used to interrupting the instructor's lecture during the class." (PD)

- "Another thing, I believe it is the culture difference why Chinese students are reluctant to ask questions during the class (to some extent, it's not respectful to interrupt the class process)." (PD) 
- "And, for Chinese student, we seldom ask question on class, we need time to think." (UA)

- "I feel unconfident and nervous to ask a question in front of all the students in class." (UA)

On Item D: Participating in class discussions:

- "I think I may have public disease so that I am afraid to share my opinions in public." (UA)

On Item E: Participating in group work in class:

- "We didn't have many group works in class (in China). It was unfamiliar to me to work with classmates." (UA)

- “I don't like group work. I prefer work by myself." (UA)

- "Not very familiar with this type of study." (UA)

- "II am uncomfortable in group work." (UA)

In contrast with the results for Items $\mathrm{C}, \mathrm{D}$, and $\mathrm{E}$, interestingly, is the result for Item $\mathrm{G}$ that only $18 \%$ of the students have difficulty seeking help from the instructor outside of class, presumably because language issues can be more easily overcome in a one-on-one situation. The students are able, evidently, to narrow the cultural power distance they bring from China in individual meetings with instructors here.

While Hofstede's cultural elements do not necessarily play a significant role in the statistics on Item F in Table 4, the results are, however, influenced by culture in a significant way. Some student comments help illustrate this.

On Item F: Forming study groups with non-Chinese classmates:

- “...always tend to form a Chinese circle/or think Americans don't have the intentions to be friends/or just shy."

- "The assignment is not that hard, and there are many Chinese students."

- "Local classmates seems slightly not willing to choose a foreign student as teammate."

- "It seems that people from different countries have their own social circles."

- $\quad$ "To become close friend with non-Chinese student is a big challenge because it is so easy to hang out with Chinese student and it's hard to walk out of comfort zone."

The data on Item $\mathrm{F}$ in Table 4 and these comments suggest that many Chinese students find it difficult to form study groups with their American classmates, and that it is much easier to study with familiar fellow Chinese, where there are no 
language or other cultural differences. A result of this is that some of the diverse cultural benefits of having Chinese students on campus and as classmates are lost.

As stated above, to complete the survey, participants were given the option to comment on the most challenging academic issues they have had as transfer students. A sample of those comments, which summarizes and highlights the main points of the article, follows.

- "In the first one or two months after I started my study here, I felt the biggest challenge is from the language. My oral skill didn't support me to express my ideas efficiently. In addition, we learnt the important and basic concepts in Chinese. It took me some time to map these concepts to English terms. I usually had to read the textbook for several times after classes to understand the content. Another challenge for me was group work in class. Speaking in English was absolutely one reason. However, we didn't have enough training back in China to come up with an idea quickly. I felt I had nothing to say. Also, we only had midterm and final exams, assignments and some labs in my university in China. We didn't have lots of exams or quizzes during the semesters. It felt exhausting to prepare the quizzes every week. It took me some time to adapt this new learning style."

- "First, reading assignment. Even though we had English reading training all the time in China, it still can overwhelmed the first time we read English textbooks or academic papers. Second, project coursework. Because of lack of engineering hands-on experiences as well as working experience before, it is difficult to catch up with most American students' project making skills.

- "First, it's hard to follow with teachers when I first came here. Second, the exams and homework here are much more than I have before. Third, it's hard to discuss with foreign students."

\section{CONCLUSION}

\section{Summary}

A survey-based study was conducted to determine answers to the question "What are the academic challenges encountered by our Chinese engineering transfer students?" Demographic background questions determined that the students in question come from all over China and from many universities throughout that country.

Survey questions aimed at comparing the college classroom learning environments of China and the United States suggested that there are significant differences between the two in every one of the nine items considered, the most significant being in the use of detailed course syllabi, class time spent on class discussion, and the numbers of assignments and graded exams. Quoted student comments support these ideas. The differences in all 11 items can be associated with 
either or both of the two of Hofstede's cultural elements that defined our theoretical framework for the project, i.e., large versus small power distance, and large versus small uncertainty avoidance.

Survey questions designed to determine the academic difficulties experienced by the Chinese transfer students showed that among the eight items considered, the most difficult were: obtaining correct and timely transfer credit for courses taken in China; understanding the instructor's English during class; asking questions and participating in group work during class; and forming study groups with non-Chinese classmates. Quoted student comments also support these ideas. Reasons for these academic difficulties include the language fluency problem and other interrelated cultural differences, including Hofstede's power distance and risk avoidance cultural elements.

The results obtained here generally agree with the material discussed in the Literature Review, but they add to it in several ways. For example, Zhang and Xu (2007) discussed the seriousness of the syllabus issue, but they did not relate it to the transfer credit problem. Similarly, they discussed difficulties that Chinese international students have with classroom discussions and asking and answering questions, but they did not discuss participation in group work in the classroom, an effective and popular form of student-centered learning. Also, as summarized in the Literature Review, Ozturgut and Murphy (2009), Henze and Zhu (2012), and Ching et al. (2017) discussed many of the difficulty areas studied in this project, but not with any statistics to illustrate the relative seriousness of those items, as has been done here. Finally, as discussed above, the students surveyed here were all in engineering, which differs from all the studies reviewed in the Literature Review, and which provides the basis for a follow-on study of Chinese transfer students from disciplines outside engineering, for comparison. For example, as noted in the section on academic adjustment difficulties, the disparity between difference data and difficulty data for certain items may reflect a characteristic of engineering students. A followon study could address that issue.

\section{Recommendations}

Given these issues and the previously discussed fact that Chinese and other international transfer students provide significant economic and cultural benefits to the campus and local communities, much can and should be done by campus and college administrations, campus and college international centers, host students, and even transfer students themselves to ease some of the identified academic challenges that those transfer students encounter. As a result, their time here will be more productive and less stressful and frustrating, which should enhance their learning outcomes and contribute to a richer intercultural experience for the Chinese transfer students, other international students, and their American hosts.

To improve the accuracy and timeliness of the transfer credit assignment process, responsible host campus officials (e.g., the registrar's office) need to convince appropriate academic officials at the transfer students' home institutions in China of the benefits to their students of providing detailed course syllabi. 
To improve transfer students' fluency in English, which will ease their difficulties in several areas, the university admissions offices should consider raising TOEFL and other language proficiency exam score requirements for transfer applicants. In addition to this, campus and college international centers need to make (greater) efforts to encourage (greater) interaction between international and American students. American students need to be made (more) aware of the intercultural opportunities at their disposal, and transfer students need to be encouraged to leave their "comfort zones" where "it is so easy to hang out other Chinese students," as one student comment stated, and immerse themselves in the diverse student body, where language skills can be improved. Along with this, college administrations need to encourage the American host students to leave their own comfort zones and be more welcoming to and patient with the international students.

To ease the transfer students' adjustment to the American classroom culture, campus and college international centers need to make (greater) efforts to ensure that Chinese transfer students are aware of the cultural classroom differences to be encountered, including: the importance of the course syllabus; the technical rigor to be expected; the numbers of graded assignments, quizzes, and exams to be expected; and the emphasis on participation in class discussions and group work. This can be done, for example, during welcome/orientation sessions, and/or via mentoring activities (Ching, et al., 2017; Ozturgut \& Murphy, 2009).

\section{REFERENCES}

Aubrey, R. (1991). International students on campus: A challenge for counselors, medical providers, and clinicians. Smith College Studies in Social Work, 62, 2033.

Berry, J. W., Kim, U., Minde, T., \& Mok, D. (1987). Comparative studies of acculturative stress. International Migration Review, 21(3), 491-511.

Chao, C. (2017). An examination on the Chinese students' rationales to receive their higher education in the U.S. World Journal of Education, 7(3), 41-49.

Chao, C., \& Hegarty, N. (2014). Driving forces which enthuse the continuous growth of Chinese students in U.S. colleges: A preliminary study on Chinese students' motives. Journal of Academic Administration in Higher Education, 10(2), 2734.

Chao, C., Hegarty, N., Angelidis, J., \& Lu, V. (2017). Chinese students' motivations for studying in the United States. Journal of International Students, 7(2), 257269.

Ching, Y., Renes, S., McMurrow, S., Simpson, J., \& Strange, A. T. (2017). Challenges facing Chinese international students studying in the United States. Educational Research and Reviews, 12(8), 473-482.

Gebhard, J. G. (2012). International students' adjustment problems and behaviors. Journal of International Students, 2(2), 184-193.

Griner, J., \& Sobol, A. (2014). Chinese students' motivations for studying abroad. The Global Studies Journal, 7(1), 2-14.

Henze, J., \& Zhu, J. (2012). Current research on Chinese students studying aboard. Research in Comparative and International Education, 7(1), 90-104. 
Hofstede, G. (1997). Cultures and organizations: Software of the mind. McGraw Hill. Liao, K. Y., \& Wei, M. (2014). Academic stress and positive affect: Asian value and self-worth as moderators among Chinese international students. Cultural Diversity and Ethnic Minority Psychology, 20(1), 107-115.

Liu, X. (2014). Comparison on the developmental trends between Chinese students studying abroad and foreign students studying in China. Journal of International Students, 4(1), 34-47.

Montgomery, K. A. (2017). Supporting Chinese undergraduate students in transition at U.S. colleges and universities. Journal of International Students, 7(4), 963989.

Ozturgut, O., \& Murphy, C. (2009). Literature vs. practice: Challenges for international students in the U.S. International Journal of Teaching and Learning in Higher Education, 22(3), 374-385.

Redmond, M. V. (2000). Cultural distance as a mediating factor between stress and intercultural communication competence. International Journal of Intercultural Relations, 24(1), 151-159.

Schlossberg, N. K., Waters, E. B., \& Goodman, J. (1995). Counseling adults in transition: Linking practice with theory (2nd ed.). Springer.

Tang, X., Collier, D. A., \& Witt, A. (2018). Qualitative study on Chinese students' perception of U. S. university life. Journal of International Students, 8(1), 151178.

Tas, M. (2013). International students: Challenges of adjustment to university life in the U.S., International Journal of Education, 5(3), 1-9.

Wu, H., Garza, E., \& Guzman, N. (2015). International students' challenge and adjustment to college. Education Research International, 2015, Article 202753. http://dx.doi.org/10.1155/2015/202753

Yen, R. T. (1987). Foreign language teaching in China: Problems and prospects, Canadian and International Education, 16, 48-61.

Yuan, W. (2011). Academic and cultural experiences of Chinese students at an American university: A qualitative study. Intercultural Communication Studies, 20(1), 141-157.

Zhang, Z., \& Xu, J. (2007). Understanding Chinese international graduate students' adaptation to learning in North America: A cultural perspective. Higher Education Perspectives, 3(1), 45-59.

ROBERT M. O'CONNELL, $\mathrm{PhD}$, is a Professor in the Electrical Engineering and Computer Science Department at the University of Missouri. His major research interests lie in the areas of electric power systems, modern teaching methodologies, and global and international education. Email: oconnellr@missouri.edu

NUERZATI RESULI, MS, is a PhD student in Electrical Engineering and Computer Science at the University of Missouri. Her major research interests lie in the areas of eldercare technologies and global and international education. Email: rnpn2@mail.missouri.edu 